\title{
Introduction to CyberResearch on the Ancient Near East and Neighboring Regions
}

\author{
Vanessa Bigot Juloux, Amy Rebecca Gansell, and \\ Alessandro di Ludovico
}

No longer does digital research impact only scientific and technical studies. It is now established as a powerful approach for revealing new information and supporting new interpretations in the humanities. Disciplines such as Archaeology, Anthropology, Art History, History, Philology, and Literary Studies have begun to benefit. Today more and more researchers of the ancient Near East, neighboring regions, and other ancient-world domains extend their traditional investigations by using digital technologies as standard and experimental tools. However, because digital research is a relatively new approach, the space dedicated to cyber-research in the humanities, especially in the study of the ancient world, is still limited and in many cases relegated to quite isolated contexts, such as specialized research centers, congresses, and conference sessions. Furthermore, until recently, critical discussions have been lacking among practitioners across projects and disciplines, and communication between cyber-researchers and traditional humanists remains inadequate. As a result, the many significant cyber-research projects that have been conducted are little known outside of specialized circles, even when their impact is relevant to the traditional humanities. Thus, a true debate about cyber-research projects and their results, impact, and potential is still missing.

Because of the great value and potential of cyber-research to the humanities overall, we hope to see its further integration into the mainstream. But if the digital humanities (DH) continue to grow along a specialized, independent trajectory, the humanities could suffer a division between digital and non-digital projects and practitioners. As a result, DH contributions to the study of human culture could become more and more inaccessible to non-DH scholars. The use of jargon and specialized digital tools (such as software and programming languages) in $\mathrm{DH}$ research can impede the accessibility of $\mathrm{DH}$ projects to non-DH scholars. However, this volume is dedicated to broadening the understanding and accessibility of DH research tools, methodologies, and results.

In an effort to build bridges among DH projects, methods, and researchers, and to invite non-digital practitioners to follow the processes and results of DH research, we have attempted to make all papers in this volume meaningful and

(C) VANESSA BIGOT JULOUX ET AL., 2018 | DOI 10.1163/9789004375086_002

This is an open access chapter distributed under the terms of the prevailing CC-BY-NC License. 
accessible to non-DH researchers as well as to DH practitioners across methodological and disciplinary silos. For instance, we hope that a computer scientist would be able to appreciate archaeological discussions and issues, an archaeologist would be able to follow philological analyses, and a humanities student would understand the logic and mechanisms of computer science techniques. To support such cross-disciplinary understanding, all papers have been peer reviewed not only for technical and factual soundness, but also for accessibility. ${ }^{1}$ In addition, we provide definitions for technical and field-specific words in glossaries at the end of the volume. ${ }^{2}$ We believe that our communicating to both extended and specialized audiences could allow the papers in this volume to inspire new ideas, research innovations, and collaborations among humanities researchers, whether or not they are "digital" specialists. We also hope that the essays could be used pedagogically, both in classroom contexts and by scholars who wish to develop or expand their own digital research toolkits. ${ }^{3}$

\section{What are Cyber-research and the Digital Humanities?}

The first step in demystifying cyber-research for the uninitiated and affirming its broad value and applications to the seasoned practitioner is a semantic one. What exactly is "cyber-research"? What is its unique value, and how is it distinguished from other forms of investigation? "Cyber" can be understood today as a generic term meaning "of, relating to, or involving computers or computer networks." ${ }^{4}$ In this sense, "cyber" can refer to many things, such as online

1 Our internal peer review committee included digital and non-digital practitioners, with specialization in the ancient Near East as well as in other historical fields and disciplines.

2 We thank our authors, especially Terhi Nurmikko-Fuller and Émilie Pagé-Perron, for their support of and assistance with the glossaries, as well as peer reviewers Massimo Maiocchi and Nathan Morello for reinforcing their significance to the volume.

3 The use of digital techniques is sometimes recommended, solicited, or even rewarded by academic institutions. Scholars who are not digital practitioners may feel ill-equipped to participate in the digital arena. However, with only a basic understanding of the logistics and problem-solving potential of $\mathrm{DH}$ procedures and instruments, it is possible for beginners to conceive of their own DH projects for which they can then seek expert collaborators and/or develop the necessary technical skills themselves.

4 We use the term "CyberResearch" in the titles of this volume and chapter as a generic, umbrella term referring to the research methods described here in their broadest sense. We propose to introduce CyberResearch as a new, formally recognized methodology that can be integrated into Ancient Near Eastern Studies as well as across the humanities (see Bigot Juloux and Ludovico 2018). Merriam Webster, s.v., "cyber," last modified January 30, 2018, <https://www. merriam-webster.com/dictionary/cyber> (accessed February 21, 2018). "Cyber" derives from the Greek stem $\varkappa$ 
shopping (Amazon.com), digital communication (email and cell phone), ${ }^{5}$ and even futuristic punk fashion. With regard to research, "cyber" indicates the use of innovative computer technologies, digital media, and algorithmic data processing to facilitate research. Computer technologies used in cyber-research go beyond the standard "front-end" use of application software such as spreadsheets, text editors, and databases; ${ }^{6}$ they require "back-end" coding in special languages to manipulate, analyze, and visualize data, ${ }^{7}$ as well as to display content on a browser (e.g., Firefox, Chrome, Safari). Algorithmic data processing involves a sequence of mathematical actions to perform tasks dedicated to solving a set of problems. When customized to solve problems that entail the processing of large amounts of data, algorithms are mostly calculated by computers, rather than by humans. ${ }^{8}$ Overall, then, cyber-research refers to investigations that rely on programming languages and/or mathematical formulas to relay data and instructions to a computer. The computer generates output that can be interpreted by researchers as results that may answer their questions,

I to describe the governance of people. See Merriam Webster (s.v., "cybernetics," second definition, <https://www.merriam-webster.com/dictionary/cybernetics $>$ [accessed February 21, 2018]): "the scientific study of how people, animals, and machines control and communicate information." The theme of control is etymologically central to the idea of cybernetics (note also the ancient Greek verb $\varkappa \mho \beta \varepsilon \rho \nu \alpha \dot{\alpha} \omega$, "to govern, to drive," the etymology of which is related to the Sanskrit kubara, "rudder"), while the common use and meaning of this and other terms belonging to the same family are due to the research and theories of the American mathematician Norbert Wiener (1894-1964), who founded the discipline now known as "Cybernetics" (Wiener 1948).

5 Digital communication is exemplified by texting on a mobile device, instant messaging (such as on Messenger and WeChat), and communication via social networking media (such as Twitter, Facebook, and LinkedIn).

6 A software application (also known as an "application program") enables the user to execute tasks on a computer. Examples of software applications used by our authors include the FileMaker (Martino and Martino) and MysQL (Pagé-Perron) databases, as well as the following text editors: Atom (Pagé-Perron), Oxygen xML Editor (Bigot Juloux), Stylus Studio (Prosser), SPAD (Ludovico), and XCode (Martino and Martino).

7 Examples of programming languages used by our authors include C++, Java, PHP, Python, SQL, XML, and XML-TEI. For an example of a graph visualization, see in this volume Pagé-Perron, 211, Fig. 6.3.

8 The word "algorithm" derives from the latinized version of the name of the Persian scholar Al-Khwārizmī (c. 780-850 CE), who brought the concept of algebra to Europe (Encyclopedia Britannica, s.v., "Al-Khwārizmī," < https://www.britannica.com/biography/al-Khwariz mi> [accessed June 8, 2017]). The immense amount of complex calculations that are often required would be impractical, if not impossible, for even the most skilled mathematician to carry out. Digital algorithmic data-processing, however, is efficient, and it can compare, manage, and integrate huge amounts of data on a very large scale. 
support or contradict their hypotheses, and/or illuminate new topics and paths of inquiry.

When cyber-research is employed to further our understanding of the humanities, it can reveal new information that is difficult or impossible to discern through the use of traditional methods. These investigations are often classified as "digital humanities" projects. According to the U.S. National Foundation on the Arts and the Humanities Act, 1965, as amended, the humanities, as a set of disciplines, includes "but is not limited to, the study and interpretation of the following: language, both modern and classical; linguistics; literature; history; jurisprudence; philosophy; archaeology; comparative religion; ethics; the history, criticism and theory of the arts; those aspects of social sciences which have humanistic content and employ humanistic methods; and the study and application of the humanities to the human environment with particular attention to reflecting our diverse heritage, traditions, and history and to the relevance of the humanities to the current conditions of national life." The digital humanities are concerned with the same topics as the humanities; where they are distinguished from the humanities is specifically in their methodologies of cyber-research. Basically, in the term "digital humanities," "digital" stands in for "cyber," referring to the computer technologies and algorithmic data processing employed as research methodologies. However, a more indepth definition of "digital humanities" is actually more ambiguous.

We are in the midst of a global technological revolution, with digital technologies appearing everywhere. ${ }^{10}$ The worldwide impact of DH is currently more prevalent in some disciplines and in some countries. ${ }^{11}$ In general, DH research has tended to begin in disciplines that intersect with the natural sciences and/or are innately rich in quantitative or text-based data; only subsequently have digital methodologies been adopted for research on more abstract material, such as art. This is currently seen, for example, in Turkey, where digital humanities is still a nascent field, and DH methodologies are mostly used in the disciplines of Comparative Literature, Linguistics, Sociology, and Political Science. ${ }^{12}$ In Finland, although the concept of DH (digitaaliset

$9<$ <ttps://www.neh.gov/about> (accessed June 9, 2017). For additional definitions of "the Humanities," see Liu (2014, <http://4humanities.org/2014/12/what-are-the-humanities/> [accessed June 9, 2017]).

"The digital revolution entered a new phase, giving rise to a vastly expanded, globalized public sphere" (Burdick et al. 2012, <https://mitpress.mit.edu/sites/default/files/titles/con tent/9780262018470_Open_Access_Edition.pdf> [accessed June 11, 2017], 2). Also see Evans and Rees 2012, 37.

11 The following discussion of the digital humanities in an international context provides examples from our authors' countries. 
ihmistieteet, literally, "digital human-sciences") is known, digitaaliset ihmistieteet is also a developing field and not widespread in its application across disciplines. As in Turkey, Finland lacks any DH centers to support research, networking, collaboration, and communication within the field. ${ }^{13}$ Through these small examples, it is evident that international opportunities are essential to the global growth of DH research.

Especially since our volume includes papers from scholars working in many different countries, where they speak many different languages, we would like to acknowledge the challenge of defining "digital humanities" for a multilingual audience by considering some examples of the complexities of international semantics. For example, "Hebrew chooses to speak about rouach digitalit, the 'digital spirit."'14 However, Italians avoid the term "digital" by saying either informatica per le scienze umane, ${ }^{15}$ which means "computer science applied in/to humanities" or "informatica umanistica," meaning "humanities computing"an expression that was actually used in English prior to the general acceptance of the term "digital humanities."16 Through the word informatica (referring to "computing" or "computer science"), one understands the point of view of the Italian scholar Enrica Salvatori, who asserts that the digital humanities are specifically a transdisciplinary approach that produces, rather than simply applies, computing tools to serve a specific purpose. ${ }^{17}$ In contrast, the French use

numériques and is mostly used in everyday speech, while the second expression refers to digital humanities for academic studies (Salah 2015, <http://sam.sehir.edu.tr/tr/series-oftalks-on-cities-buyuk-veri-caginda-dijitallesen-beseri-bilimler/\#sthash.HDpesADı.dpuf> [accessed June 10, 2017]). We thank Doğu Kaan Eraslan for this information.

"In Finland the concept of digital humanities is known but there is still fairly little of formal contribution" (Viiri, 2014, <https://talkarttalksociety.wordpress.com/category/archi ves/> [accessed June 9, 2017]). For a map and list of Digital Humanities Centers worldwide, see <http://dhcenternet.org/centers $>$ (accessed June 10, 2017).

14 Clivaz 2017, <http://digihubb.centre.ubbcluj.ro/journal/index.php/digitalia/article/view/ 4/18> (accessed June 10, 2017), 28.

15 See, for example, Ciracì (2012).

16 Ciotti 2014, <https://infouma.hypotheses.org/244> (accessed June 9, 2017).

17 "Una prima visione percepisce l'informatica — all'interno dell'endiadi Informatica Umanistica-sostanzialmente come uno strumento che non deve semplicemente essere ben applicato all'ambito delle scienze umane, ma può e deve essere dedicato ad esso, espressamente studiato per servire a uno scopo preciso ... L'informatico umanista—in questa visione punta a ottenere una rilevante specializzazione su uno o più specifici tool, su cui acquisire tutte le necessarie competenze per un loro uso corretto e funzionale allinterno di un ambito specifico di impiego" (Salvatori 2015, <https://esalvatori.hypotheses.org/ 204> [accessed June 10, 2017]). Translation by Bigot Juloux and Ludovico: "A first perspective perceives information technology—inside the hendiadys Digital Humanities- 
the terms humanités numériques and, more rarely, humanités digitales, which is the literal translation of the English term "digital humanities." ${ }^{18}$ Both expressions are translated as "digital humanities," although humanités numériques preserves reference to the "numerical," i.e., computational, nature of the research. However, if one differentiates between numérique and digitale from the perspective of French semantics, according to the semiologist Anthony Mathé, the word numérique is most typically used to refer to "digital" technologies and media, such as films and music, while the term digitale describes the use of "digital" (in the English-language sense) technology. ${ }^{19}$ The French thus

essentially as a tool that should not simply be applied accurately to the field of the humanities, but that can and must be devoted to it, specifically designed to serve a specific purpose ... The digital humanist—from this perspective-aims to obtain a relevant specialization in one or more specific tools, in order to capture all of the necessary skills for their correct and functional use within a specific scope of applications." See also a more detailed paper on this topic: Angiolini et al. (2015).

18 Humanités digitales is the literal translation of "digital humanities," following the Anglicism "digital" (Merriam Webster, s.v., "digital," updated February 15, 2018, <https://www. merriam-webster.com/dictionary/digital $>$ [accessed February 21, 2018]). See also Centre National de Ressources Textuelles et Lexicales (s.v., "digital," first definition, meaning B, 2012, <http://www.cnrtl.fr/definition/digital> [accessed June 10, 2017]), which follows the definition provided in Académie française (s.v., "digital," updated November 7, 2013, $<$ http://www.academie-francaise.fr/digital> [accessed June 10, 2017]). Valérie Carayol and her colleagues from the University of Bordeaux first used "humanités digitales" in 2008 (Clivaz, 2017, 29). Regarding the meaning of "humanités" and its semantic development, see Clivaz (2017, 31-33, 36): "As astonishing as it is, while many scholars emphasize the corporeal elements related to the use of the word 'digital/e' in its relation to the word 'humanités', they all ignore that such potential traces belong even more so to the history of the word 'humanité' itself"... [And with regard to the academic understanding,] "the French word humanités signals an humanist interdisciplinary perspective: it includes History, Letters and Political Sciences."

Ropars (2017, <http://www.blogdumoderateur.com/numerique-ou-digital/> [accessed June 8, 2017]) quotes Anthony Mathé, saying, "On parle d'industrie numérique et de pratiques digitales ... Numérique tend à renvoyer de fait au technologique, à la dimension discrète de la technologie, celle que manipulent les ingénieurs et qui restent intangible. Digital semblerait concerner plutôt l'usager dans son expérience de cette technologie numérique." Bigot Juloux's translation: "One speaks of numerical industry and digital practices ... In fact, numerical refers to technology, to the discrete scope of the technology, the one that engineers manipulate and that remains intangible. Digital would rather appear to concern the user in his experience of this numerical technology." For additional discussion, see Histoires de Digital Makers blog post (February 27, 2015), "Digital' or 'Numerique?' A New Linguistic Debate Rages in France" (<https://www.digitalforallnow. com/en/digital-numerique-linguistic-france/> [accessed June 8, 2017]). 
speak of pratiques digitales (digital practices), technologies numériques (digital technologies), and, whether they are digitales (in either the French or English sense) or numériques, the French scholar Aurélien Berra has definitively recognized humanités digitales as a research practice. ${ }^{20}$ Today, in France and internationally, numérique(s) or digitale(s) research is extended from science into humanities practice. ${ }^{21}$

In any language, the term "digital humanities" (and its equivalents and nearequivalents) is quite new. Its meaning and scope are not yet agreed upon, even within English usages. Although a pioneering wave of digital humanities scholarship took place in the late $1990{ }^{22},{ }^{22}$ the term "digital humanities" was first introduced to the academic community by John Unsworth (from the University of Virginia) in 2001, when he proposed a new Master's degree program called "Digital Humanities." 23 The same year, in collaboration with the editorial and marketing teams at Wiley-Blackwell, he also developed the title A Companion to Digital Humanities, for a volume on what, at the time, was commonly called

20 In the words of Aurélien Berra (2012, <http://books.openedition.org/oep/238> [accessed June 9, 2017], 25-43): "Les humanités numériques sont donc principalement une pratique de recherche." Translation by Bigot Juloux: "Digital humanities are therefore primarily a research practice."

21 For further discussion of the French translation, see Clivaz (2017, 29-33).

22 Presner 2010, <https://cnx.org/contents/JoK7N3xH@6/Digital-Humanities-2o-A-Report> (accessed June 9, 2017). But the premise of the digital humanities can be dated to 1949 when the Jesuit scholar Roberto A. Busa was preparing materials on St. Thomas Aquinas for the Index Thomisticus project, a computer-generated concordance produced in collaboration with IBM (Busa 2004, xvi-xvii; Burdick et al., 2012, 123). See also the University College London project "Hidden Histories: Computing and the Humanities c. 1949/1980" (<http://www.ucl.ac.uk/infostudies/research/ hiddenhistories/> [accessed June 8, 2017]).

23 Unsworth considered but intentionally avoided the terms "Humanities Informatics" and "Humanities Computing." For the draft proposal for the degree, see <http://www.people. virginia.edu/ jmu2m/laval.html> (accessed June 8, 2017). The degree, however, was never realized (Kirschenbaum 2012, <http://dhdebates.gc.cuny.edu/debates/text/48> [accessed June 8, 2017], 418). For the emergence of DH, see Bernard (2012, <http://books. openedition.org/oep/242> [accessed June 7, 2017], 45-58) and Hockey (2004). To quote The Digital Humanities Manifesto 2.0 (<http://manifesto.humanities.ucla.edu/2009/05/29/ the-digital-humanities-manifesto-20/> [accessed June 7, 2017]): "Digital Humanities is not a unified field but an array of convergent practices that explore a universe in which: a) print is no longer the exclusive or the normative medium in which knowledge is produced and/or disseminated; instead, print finds itself absorbed into new, multimedia configurations; and b) digital tools, techniques, and media have altered the production and dissemination of knowledge in the arts, human and social sciences." 
"humanities computing." ${ }^{24}$ While Berra has asked the question of whether DH constitutes a type of practice or methodology, or whether it is a field, ${ }^{25}$ Christine Borgman maintains that it addresses research problems in humanities disciplines using new sets of technologies. ${ }^{26}$ Frederic Darbellay has suggested that DH refers to the junction between new information technologies and humanities' disciplines. ${ }^{27}$ Matthew Kirschenbaum has raised the question "What is (or are) the 'digital humanities,' aka 'humanities computing'?"28 and for Eileen Gardiner and Ronald Musto "digital humanities" refers to a methodology, while "humanities computing" is a field. ${ }^{29}$ Meanwhile, Patrik Svensson has proposed that "humanities computing ... is largely a common interest in methods, methodology, tools and technology." 30 Amidst this debate, referring to the initial goal of the "computing humanities," David Berry has suggested that we should consider "digital humanities" as "a technical support to the work of the 'real' humanities scholars, who would drive the projects." ${ }^{31}$ Indeed, there are so many apparent "definitions" of "digital humanities" that Jason Heppler has established a website dedicated to compiling how different people have defined the term. ${ }^{32}$ Also, there is an annual international "Day of DH" (established in 2009), during which anyone can electronically submit questions to the DH

24 Kirschenbaum 2010, <https://www.ade.mla.org/bulletin/article/ade.150.55> (accessed June 7,2017$), 5^{6-57}$. The volume bearing the seminal title (coined in 2001) A Companion to Digital Humanities was not published until three years later (Schreibman 2004).

25 Berra 2012.

26 "The digital humanities is a new set of practices, using new sets of technologies, to address research problems of the discipline" (Borgman 2009, <http://digitalhumanities.org/dhq/ $\mathrm{vol} / 3 / 4 / 000077 / 000077 \cdot \mathrm{html}>$ [accessed June 10, 2017]).

“'Digital humanities' désignent la rencontre entre les nouvelles technologies de l'information et de la communication et les disciplines des sciences humaines et sociales, des arts et des lettres" (Darbellay 2012, <https://www.nss-journal.org/articles/nss/abs/2012/03/ nss120033/nss120033.html> [accessed June 7, 2017], 269). Bigot Juloux's translation: "Digital humanities means the meeting between new information and communication technologies and the disciplines of the humanities and social sciences, arts and literature." "Humanities computing as a whole maintains a very instrumental approach to technology in the Humanities" (Kirschenbaum 2010, 55).

29 Gardiner and Musto 2015, 4.

30 Svensson 2009, <http://digitalhumanities.org/dhq/vol/3/3/000065/000065.html > (accessed June 10, 2017).

31 Berry 2011, <http://www.culturemachine.net/index.php/cm/article/viewarticle/440> (accessed June 7, 2017), 2.

32 See: <http://www.whatisdigitalhumanities.com> (accessed February 22, 2018). A new definition is displayed with each refresh of the screen. 
community. ${ }^{33}$ In the early years, it was asked, "How do you define Humanities Computing/Digital Humanities?"34 Since 2013, a new question has arisen: "Just what do digital humanists do?"35A major point of debate concerns which cyber-research methods fall under the umbrella of $\mathrm{DH} .{ }^{36}$ From some perspectives, DH incorporates all aspects of cyber-research, including any techniques borrowed from Natural Sciences, Engineering, Applied Mathematics, and Computer Science. Other points of view exclude computer-science techniques from the domain of the digital humanities and prefer to say that computer science can be integrated as a tool in the process of DH analyses; others specifically see coding but not algorithmic formulas as DH tools. Perhaps a compromise would be to follow the Stanford Humanities Center's broad definition of digital humanities as a "hybrid domain ... at the crossroads of computer science and the humanities." 37

Because the very definition of $\mathrm{DH}$ is unstable, research falling under the broadest definition of digital humanities is not necessarily classified as such according to narrower definitions (for example, a project may be described as a Computer Science, rather than a DH, investigation). The threshold for classifying humanities research as "digital" is also ambiguous. For instance, research using front-end technologies, such as automated functions in off-the-shelf software, is sometimes - but not typically-accepted as technically rigorous enough to be described as digital humanities versus humanities research. For example, virtual-reality ancient world simulations, projects that produce $3^{\mathrm{D}}$ scans of sites, objects, and texts, as well as archaeological investigations that collect and disseminate data through digital rather than manual methods, are

A Day in the Life of the Digital Humanities is an open community publication (Rockwell et al. 2012, <http://www.digitalhumanities.org/dhq/vol/6/2/ooo123/o00123.html> [accessed February 22, 2018]). For Day of DH 2017, see $<$ http://dayofdh2017.linhd.es/ $>$ (accessed February 22, 2018).

See "How do you define Humanities Computing/Digital Humanities?" (wiki page of the University of Alberta, last updated March 16, 2011, <http://www.artsrn.ualberta.ca/tapor wiki/index.php/How_do_you_define_Humanities_Computing_/_Digital_Humani ties\% ${ }_{3} \mathrm{~F}>$ [accessed, August 17, 2017]).

35 See the welcome page on the Day of DH 2014 website, <http://dayofdh2014.matrix.msu. edu/> (accessed, August 17, 2017).

36 Presner 2010; Alvarado 2012, 50.

37 See $<$ http://shc.stanford.edu/digital-humanities $>$ (accessed June 8, 2017). Also consider: "Digital humanities is by its nature a hybrid domain, crossing disciplinary boundaries and also traditional barriers between theory and practice, technological implementation and scholarly reflection" (Flanders, Piez, and Terras, 2007, <http://digitalhumanities.org/dhq/ $\mathrm{vol} / 1 / 1 /$ ooooo7/000007.html $>$ [accessed June 10, 2017]). 
sometimes described as DH enterprises. Even more "traditional" uses of digital products could be considered to fall within the scope of DH research, since the cognitive and sensorial perception of digital objects is so different from the experience of working with concrete, material sources of information. Finally, some views only refer to research conducted in specific branches of the humanities as DH research. In particular, there is a notion that DH research is specific to textual and literary corpora. ${ }^{38}$ Clearly, the boundaries of the digital humanities are not yet solidified. In order to avoid debates over what is or is not a DH project, and so that we do not perpetuate confusion, this volume equates all of its projects with cyber-research. That is, all of the papers presented here exemplify cyber-research methodologies for humanities investigation. ${ }^{39}$

\section{Overview of the Volume}

With this volume, we specifically hope to intervene in a scholarly landscape in which DH research has had a less-than-optimal impact upon the general narratives of ancient history.

Here we present some of the latest interdisciplinary research projects in which cyber-methodologies (including computational and computer science techniques) play a central role in the investigation of humanities-based questions about ancient Near Eastern and surrounding cultures from the Chalcolithic period through the Iron Age. The 11 contributions collected here represent the work of archaeologists, anthropologists, art historians, and philologists,

38 Regarding digital humanities and text analysis, see Tüfekçi $(2015,<$ http://monografjour nal.com/sayilar/4/yazinsal-calismalarda-dijital-yonelimler-monograf-sayi-4.pdf> [accessed June 7, 2017], 92): “İnsani bilimlerde dijital yönelimler çerçevesinde geliştirilen çözümleme yöntemleri belirli bir izlek, bakış açısı ve ileti kaygısı sınırlaması taşımadan metnin iskeletini ve buna bağlı tüm verileri olduğu gibi görselleştirerek yeni çalışmaların kullanımına sunup belirli bir görüşü dayatmayan yeni okumaların, yeni metinlerin oluşmasını sağlar." Eraslan's translation: "Analytical methods with digital orientations that are developed in the humanities provide new readings- new texts that do not impose a predefined view, by visualizing the skeleton of the text and all the data related to it without limiting itself to predefined notions, points of view, and to a worry for a message." By saying "worry for a message," Tüfekçi means that prior biases do not impact one's statements.

39 "Digital Humanities is defined by the opportunities and challenges that arise from the conjunction of the term digital with the term humanities to form a new collective singular" (Burdick et al., 2012, 122). 
many of whom also engage methods and theories derived from other disciplines, such as Philosophy and Geography. Most of the papers were introduced at the 2016 and 2017 annual meetings of the American Oriental Society (AOS), the American Society for Oriental Research (ASOR), and Computer Applications and Quantitative Methods in Archaeology (CAA). ${ }^{40}$ To round out the volume and facilitate cross-fertilization among topics and methodologies, a few additional papers were independently solicited. All essays, however, have been written or revised (from their conference sessions) to fit the mission and framework of this volume.

The book is divided into four parts: "Archaeology," "Objects," "Texts," and "Online Publishing, Digital Archiving, and Preservation." The first part, "Archeology," presents papers dealing with data related to fieldwork activities, entire sites, and landscape archaeology, while part II, "Objects," focuses on specific corpora of material culture. The papers in part III, "Texts," employ written documents as primary sources for information discovery. Then, through three text-based case studies, part IV, "Online Publishing, Digital Archiving, and Preservation," addresses the value of sharing and publishing data online. Such data sharing and publishing not only creates an electronic record of ancient evidence, but it also facilitates collaboration and provides an efficient basis for future research. ${ }^{41}$

Across the four parts of this volume, the reader will find connections among the projects presented in the chapters. For example, in part III ("Texts"), chapter 5 includes a section, "Analytical Taxonomies in TEI," that relates to methods employed in projects discussed in parts I ("Archaeology"), II ("Objects"), and IV ("Online Publishing, Digital Archiving, and Preservation"). To facilitate the study of methods and tools used across projects, cross-references are provided in the chapters. Although the authors of each chapter employ unique approaches to examine specific topics, all participate in the domain of cyber-research and complement one another with humanities contributions to the study of the ancient Near East and neighboring regions.

\footnotetext{
40 ASOR: <http://www.asor.org/>; CAA: <http://caa-international.org/>; AOs: <https://www. americanorientalsociety.org/> (all accessed June 9, 2017).

41 "Digital technology can enhance the preservation of artifacts by providing superlative surrogates of original sources while at the same time protecting the artifact from overuse" (Smith, 2004, <http://digitalhumanities.org:3030/companion/view?docId=blackwell/9781 405103213/9781405103213.xml\&chunk.id=ss1-5-7\&toc.depth=1\&toc.id=ss1-5-7\&brand= 9781405103213_brand > [accessed August 18, 2017], 589). Also, according to Paul Conway (1996, <https://www.clir.org/pubs/reports/conway2/index.html\#gen8> [accessed August $18,2017])$, digital preservation is made through digital imagery technologies "to protect original items."
} 
In the first part, "Archaeology," two papers explore new approaches to excavation data and data recording. In chapter 1, Sveta Matskevich and Ilan Sharon investigate the excavation records of Tel Dor in Israel and reflect upon the conceptual basis of archaeological data recording. They address questions such as: How can data be best digitized and curated for the long-term? And can interoperability among different registration systems be achieved? In response, they seek a common denominator and logical structure for all excavation-recording systems and "present the new idea of [a] graph database" as a means of organizing disparate records. ${ }^{42}$ Moving from matters of recording archaeological data to interpreting it, chapter 2, by Marco Ramazzotti (in collaboration with Paolo Massimo Buscema and Giulia Massini), presents the innovative approach of applying Artificial Intelligence models to landscape archaeology records in order to test Mesopotamian Urban Revolution theories. This research "enhances [our] understanding of complex cultural processes in ancient anthropic contexts,"43 as it reveals previously unidentified interrelations during the four periods (Ubaid, Uruk, Jemdet Nasr, and Early Dynastic) of the Mesopotamian Urban Revolution through an analysis of archaeological settlement data. The results move us beyond traditional perspectives by providing "new insight into the current knowledge on the settlement processes in Lower Mesopotamia." 44

Part II, "Objects," also contains two chapters. In chapter 3, Alessandro di Ludovico considers a corpus of late third-millennium BCE (Ur III period) Mesopotamian cylinder seal imagery. Using encoding and software-assisted correspondence analysis, he develops descriptions, classifications, interpretations, and comparisons among presentation scenes depicted on seals and seal impressions. The results of his "analysis both add to current scholarly reconstructions of the role that geographic distribution (among other factors) plays in glyptic traditions and effectively demonstrates the application of quantitative and automated methods in the study of the ancient Near East." 45 Chapter 4 shifts in focus from images to artifacts. Here, Shannon Martino and Matthew Martino work with third-millennium BCE Early Bronze Age figurines and ceramics from Turkey. They question subjectivity and objectivity, then propose a

42 We asked our reviewers to indicate how our authors' methodologies contribute to various scholarly domains and may help to motivate and support new investigations. In the following summaries of the chapters, we quote, with their kind permission, some of the reviewers' statements. Here we quote reviewer Sergio Camiz.

44 Here we quote reviewer Francesca Cioè.

45 Here we quote reviewer Andrew Pottorf. 
methodology for classifying figurines and ceramics to build a typology based on common attributes. Their method implies a strong collaboration between programmers and archaeologists, thus showing the vital benefits of interdisciplinarity. The Martinos' project presents "a very interesting possibility to deal with typological analyses in a somewhat more objective fashion," ${ }^{26}$ and it offers a new model that is "potentially useful for a preliminary classification of a large variety of archaeological artefacts." 4

Part III, "Texts," contains four chapters covering three millennia of writing in Ugaritic, Sumerian, and Akkadian. Chapter 5, by Vanessa Bigot Juloux, explores actions between characters in a second-millennium BCE Ugaritic myth ('Anatu in the Balu and 'Anatu Cycle [KTU 1.1-6]) in order to set up a "hermeneutics of action," as well as to investigate gender-related roles. She encodes the text using "markup language to allow an ... automatic analysis,"48 and her results "really show how actions within verbs are complex." ${ }^{" 49}$ Next, in chapter 6, Émilie PagéPerron situates us in Mesopotamia with a corpus of third-millennium BCE Old Akkadian texts. She employs network analysis to reveal labor structures and relationships among individuals mentioned across the corpus. Both her methods and results "may help to formulate new scientific questions and create new fields of investigations." ${ }^{50}$ Chapter 7 , by Saana Svärd, Heidi Jauhiainen, Aleksi Sahala, and Krister Lindén, uses statistical methods to analyze semantic fields in Akkadian vocabulary and thereby understand cultural meaning from ancient, emic perspectives. "The paper proves to be the first step of a potentially huge contribution to the philological and historical research of the ancient Near East."51 Its methodology could confront "many important open questions in our field," 52 and "the use of text to understand the cultural mores of ancient cultures [also] has interesting implications for archeology." ${ }^{\prime 3}$ In the final paper (chapter 8) of part III, M. Willis Monroe employs computer-aided textual analysis to discover patterns of associations among astrological cuneiform documents created under Achaemenid and Hellenistic rule in Babylonia from the late sixth to second century вСE. While bringing an intriguing "Micro-zodiac"

\footnotetext{
$46 \quad$ Here we quote reviewer Matthew Vincent.

47 Here we quote an anonymous reviewer.

48 Here we quote reviewer Sergio Camiz.

49 Here we quote reviewer Anne-Caroline Rendu Loisel. Her original comment was in French: "des différentes catégories qui montrent bien la complexité des actions dans les verbes" (translation by Bigot Juloux).

50 Here we quote reviewer Marine Béranger.

$5^{1} \quad$ Here we quote reviewer Nathan Morello.

$5^{2} \quad$ Here we quote reviewer Nathan Morello.

53 Here we quote reviewer Aaron Gidding.
} 
text to light, his results contribute to the understanding of ancient scholarly practices behind the composition and editing of these astrological records. Monroe's project "shows the feasibility of applying digital humanities methods to a fragmentary, specialized corpus ... [and the benefits of digital analysis in] removing the idiosyncratic ... biases an Assyriologist might bring to the analysis of lists of technical vocabulary." ${ }^{\prime 4}$

Our volume closes with part IV, "Online Publishing, Digital Archiving, and Preservation," which celebrates the value and future prospects of making cyber-research data, methodologies (including algorithms and code, for example), and results freely accessible online to worldwide audiences. The three chapters in this part present exemplars of text-based research, but they also offer methods and standards applicable to any sort of cyber-project, including those in different fields and disciplines across and beyond the humanities. Chapter 9, by Doğu Kaan Eraslan, considers the problem of the multilingual interoperability of encoding schemes through a case study of the quadrilingual vase of the ancient Persian king Darius I (r. 522-486 вСE). The vase bears four inscriptions, which are written with Elamite cuneiform, Akkadian cuneiform, Egyptian hieroglyphs, and Old Persian cuneiform. Eraslan explores how to best encode these ancient texts across languages, keeping in mind epigraphic accuracy as well as the importance of conserving information about the physical features of the inscribed object and the writing itself. "The potential of the approaches described in the paper is huge, as it may open up new avenues of research, crossing data from multilingual corpora-a desideratum in the Humanities." 55 In chapter 10, Miller C. Prosser introduces the Ras Shamra Tablet Inventory (RSTI), a project aimed at creating reliable digital editions of the texts in the Ras Šamra-Ugarit corpus within a research database environment that also seeks to integrate archaeological data from the excavations at Ras Šamra. The Online Cultural and Historical Research Environment (OCHRE), an online database environment, is used to add new data to RSTI, allowing project members to have immediate, live access to the data. OCHRE "allows researchers to edit their data so that it is 'Linked Data' ready ... and it enables researchers to do this themselves, without necessarily having to ask a programmer to help them." ${ }^{56}$ Finally, in Chapter 11, through a case study of the Electronic Text Corpus of Sumerian Literature (ETCSL), Terhi Nurmikko-Fuller demonstrates the benefits of Linked Data and online publication for philological, museological, curatorial, and archaeological data. Nurmikko-Fuller "introduces a novel

55 Here we quote an anonymous reviewer.

$5^{6}$ Here we quote author and reviewer Terhi Nurmikko-Fuller. 
method ... to create linked ontologies for digitized cuneiform texts [that] ... will be a valuable application to additional cuneiform datasets online. ${ }^{n 7}$ This paper "is of broader interest than the simple publishing of a single corpus, because it shows clearly the impact that the data and their methodological treatment can have for the evolution and progress of ... [cyber-]technologies and their usability by researchers and curators alike." 58 Nurmikko-Fuller's chapter thus represents the spirit and potential of sharing data, knowledge, and knowledge-discovery techniques that this volume and all of its contributions embrace and aim to inspire.

\section{What Does That Mean? Check Our Glossaries!}

It is necessary to speak the same language in order to communicate and collaborate productively, but the accessibility of both cyber-research and ancient world studies is hampered by specialized terminologies. This volume, however, aims to overcome this hurdle. To accommodate the diverse experience and expertise of our readers, jargon from all domains, ranging from Mathematics and Computer Science to Archaeology and Ancient Near Eastern Studies, is either defined in footnotes or, when the terminology has a broad usage across the volume, is defined in our customized CyberResearch and General (ancient world) Glossaries.

The CyberResearch Glossary includes computer science, mathematical, and technological terms. It contains definitions and practical examples quoted from the essays. In some cases, a term has specific meanings in the contexts of different methodologies. For example, in addition to its generic definition, the term "node" has a specific function within the approaches of four of our essays (see the contributions of Bigot Juloux, Pagé-Perron, Prosser, and NurmikkoFuller). On account of such specific usages, the CyberResearch Glossary aims to clarify the meaning of technical terminology both for neophytes and for specialists who may not recognize the specialized usage of a familiar term in a new domain.

The General Glossary includes terms from Archaeology, History, Geography, Literature, and Philology. Its goal is to support readers who are not ancient world specialists, but who wish to study the application of digital methods to humanities research. Among these readers, we hope, would be self-educators as well as instructors and students from diverse disciplines and fields in

$57 \quad$ Here we quote reviewer Adam Anderson.

$5^{8}$ Here we quote reviewer Jean-Baptiste Camps. 
humanities and DH programs who participate in cyber-research courses on subjects such as Python, ${ }^{59}$ the analysis and visualization of data with $\mathrm{R}$, digital philology and quantitative methods, web semantics (RDF and SPARQL), and XML data using XPath and XQuery. To date, such courses lack broadly accessible case studies that provide practical examples of the application of cyber-research methods in non-scientific fields. Such material would be of particular pedagogical value, since the digital humanities, as an interdisciplinary field of teaching, fosters the "theoretical consideration and practical progress of interdisciplinarity with the new mode of production and dissemination of knowledge." ${ }^{\circ 0}$ We hope the projects presented in this volume may help fill this gap in pedagogical materials, since diverse, concrete examples of DH projects can be very useful training resources that would broaden the sample of methodologies to be studied and compared across disciplines.

59 Some international examples of digital humanities programs include Stanford University's undergraduate minor in Digital Humanities (<https://dhminor.stanford.edu/> [accessed August 18, 2017]), the Australian National University's undergraduate major and minor in Digital Humanities, as well as its Master's degree in Digital Humanities and Public Culture (<http://cdhr.anu.edu.au/> [accessed August 18, 2017]), and King's College London's MPhil and PhD in Digital Humanities (<https://www.kcl.ac.uk/study/postgrad uate/research-courses/digital-humanities-research-mphil-phd.aspx> [accessed August 18, 2017]). Also, Paris Sciences et Lettres (PSL) offers an interdisciplinary Master's degree in Digital Humanities with an especially broad pedagogical reach for students with a bachelor's degree in a humanities field. The courses are also open to $\mathrm{PhD}$ candidates, postdoctoral fellows, and established researchers from several institutions and research centers that are members of PSL, including Collège de France, École Nationale des Chartes, École des Hautes Études en Sciences Sociales, École Normale Supérieure, École Pratique des Hautes Études, École Française d'Extrême Orient, Le Centre national de la recherche scientifique (CNRS, the French National Center for Scientific Research), and INRIA (the French National Institute for Computer Science and Applied Mathematics). These French universities and centers include several humanities fields covering prehistoric through contemporary periods.

60 "Les Digital Humanities se présentent comme un champ interdisciplinaire d'enseignement et de recherche qui a pour ambition de connecter les réflexions théoriques et les avancées pratiques de l'interdisciplinarité avec les nouveaux modes de production et de diffusion des connaissances" (Darbellay, 2012, 270). English translation by Bigot Juloux: "Digital humanities can be described as an interdisciplinary field of teaching and research that aims to interlink theoretical reflections and advanced interdisciplinary practices with new modes of knowledge production and dissemination." 


\section{Conclusion: The Path Forward}

Three central, critical topics represent the milestones along the path we would like to begin to walk with this volume. First is the question of the concrete role of digital technologies and their applications in the investigation of artifacts and languages that fall into historical and cultural frames (for instance, preand early historic periods, Sumerian culture, and Ugaritic literature) that present, for modern scholars, large gaps of knowledge. A second fundamental issue to which this volume responds is the need for a wide coordination of efforts in the use and acceptance of digital technologies and their results. This is especially important for establishing collaborations and methodological debate within and beyond the DH community. We particularly aim to bring together scholarly contributions using cyber-technologies for the study of antiquity, in order to give the ancient world greater visibility and to allow for the comparison of approaches across the many disciplines and subfields of ancient world studies. Furthermore, we hope that non-DH researchers will critically engage with and potentially benefit from the outcome of DH projects, such as those presented here. Finally, we have begun to confront the complexities and challenges of functionally embedding the use of digital tools into the study of the ancient Near Eastern and other ancient world cultures. We must consider solutions for managing the rapid obsolescence of digital tools and for maintaining control of them without becoming dependent on their peculiar modes of operation-or on information technology (IT) specialists who, in the manner of modern scribes, sometimes hold the exclusive knowledge of their logistics and mechanisms. It is also necessary to establish models for preserving digital products, such as databases and interactive visualizations, in order to keep them active, usable, and open for users in the long term.

Digital technology has changed our world. The ways we read, write, learn, communicate, and play have fundamentally changed due to the advent of networked digital technologies. ${ }^{61}$

Even though today the "digital" and "traditional" humanities are still different enterprises, ${ }^{62}$ in a near future it is likely that "digital," including "cyber"

61 Here we quote the U.S. National Endowment for the Humanities, see $<$ https://www.neh. gov/divisions/odh/about> (accessed June 10, 2017).

62 By "traditional" we understand the "practice" as "a way of thinking, behaving, or doing something that has been used by the people in a particular group, family, society, etc., or a long time" (Merriam Webster, s.v., "traditional," updated February 15, 2018, 
methodologies, will become integral to humanities research. ${ }^{63}$ In 2013, William Pannapacker even predicted that "we'll lose the 'digital' [from 'digital' humanities] within a few years, once practices that seem innovative today become the ordinary methods of scholarship." During this exciting time, "digital" and "traditional" communities of scholars are beginning to communicate, collaborate, and restructure the methods, theories, and expectations of the humanities. ${ }^{64}$ Contributing to this shift, this volume eagerly supports the assimilation of "cyber" methodologies into general humanities practices.

In conclusion, differentiating our efforts from many previous stand-alone DH projects, we assume the responsibility of disseminating DH methodologies and research to a broad and diverse audience for the purposes of supporting scientific cyber innovation, digital and non-digital humanities research, and classroom education. We aim to increase expert communication among highly specialized projects that are sometimes impenetrable to outsiders and to make these projects accessible to researchers who themselves are not trained in cyber-research techniques. We welcome all readers and encourage those from across disciplines to read the chapters that are both within and outside of their areas of expertise for the sake of finding new approaches to managing, studying, analyzing, visualizing, and interpreting their own data.

<https://www.merriam-webster.com/dictionary/traditional> [accessed February 22, 2018]). Differences also exist among communities within the humanities. Still relevant today, although stated over a decade ago, is this statement by Flanders, Piez, and Terras (2007): "We need to work hard to explain our work and ideas and to make them visible to those outside our community who may find them useful."

63 Pannapacker 2013, <http://www.chronicle.com/article/Stop-Calling-It-Digital/137325/> (accessed June 10, 2017).

64 According to Thomas Kuhn (1996, 84-85), "All crises begin with the blurring of a paradigm and the consequent loosening of the rules for normal research ... The transition from a paradigm in crisis to a new one from which a new tradition of normal science can emerge is far from a cumulative process, one achieved by an articulation or extension of the old paradigm. Rather it is a reconstruction of the field from new fundamentals, a reconstruction that changes some of the field's most elementary theoretical generalizations as well as many of its paradigm methods and applications. During the transition period, there will be a large but never complete overlap between the problems that can be solved by the old and the new paradigms. But there will also be a decisive difference in the modes of solution. When the transition is complete, the profession will have changed its view of the field, its methods, and its goals." 


\section{References}

Alvarado, Rafael C. 2012. "The Digital Humanities Situation." In Debates in the Digital Humanities, edited by Matthew K. Gold, 50-55. Minneapolis: University of Minnesota Press.

Angiolini, Andrea, Francesca Di Donato, Luca Rosati, Federica Rossi, Enrica Salvatori, and Stefano Vitali. 2015. "Digital Humanities: 'Crafts and Occupations.” In AIUCD '14 Proceedings of the Third AIUCD Annual Conference on Humanities and Their Methods in the DigitalEcosystem, article (5), edited by Francesca Tomasi, Roberto Rosselli Del Turco, and Anna Maria Tammaro. New York: Association for Computing Machinery.

Bernard, Lou. 2012. "Du literary and linguistic computing aux digital humanities: retour sur 40 ans de relations entre sciences humaines et informatique." In Read/Write Book 2: Une introduction aux humanités numériques, edited by Pierre Mounier, $45^{-58}$. Marseille: OpenEdition Press. <http://books.openedition.org/oep/242>.

Berra, Aurélien. 2012. "Faire des humanités numériques." In Read/Write Book 2: Une introduction aux humanités numériques, edited by Pierre Mounier, 25-43. Marseille: OpenEdition Press. <http://books.openedition.org/oep/238>.

Berry, David M. 2011. "The Computational Turn: Thinking about the Digital Humanities." Culture Machine 12. <http://www.culturemachine.net/index.php/cm/article/ viewarticle/440>.

Bigot Juloux, Vanessa, Alessandro di Ludovico. 2018. "Digital Practices vs. Digital Humanities: Reflections to Bridge the Gap in Order to Improve Research Methods and Collaboration." Paper presented at CAA annual meeting, Tübingen, Germany.

Borgman, Christine. 2009. "The Digital Future is Now: A Call to Action for the Humanities." DHQ 3 (4). <http://digitalhumanities.org/dhq/vol/3/4/000077/oooo77.html>.

Burdick, Anne, Johanna Drucker, Peter Lunenfeld, Todd Presner, and Jeffrey Schnapp, eds. 2012.Digital_Humanities. Cambridge, MA: MIT Press. < https://mitpress.mit.edu/ sites/default/files/titles/content/9780262018470_Open_Access_Edition.pdf >.

Busa, Roberto A. 2004. "Foreword: Perspectives on the Digital Humanities." In A Companion to Digital Humanities, edited by Susan Schreibman, Ray Siemens, and John Unsworth, xi-xxvii. Malden, MA: Wiley-Blackwell.

Ciotti, Fabio. 2014. "Digital Humanities in Italy and their role in DARIAH research infrastructure." Leggere, Scrivere e Far di Conto (blog), September 14, 2014. < https://infou ma.hypotheses.org/244>.

Ciracì, Fabio. 2012. Informatica per le scienze umane. Fonti scientifiche e strumenti per la ricerca storico-filosofica in ambiente digitale. Milan: McGraw-Hill.

Clivaz, Claire. 2017. "Lost in Translation? The Odyssey of 'Digital Humanities' in French." Studia UBв Digitalia 62 (1). <http://digihubb.centre.ubbcluj.ro/journal/index.php/ digitalia/article/view/4/18>. 
Conway, Paul. 1996. "Preservation Management in the Digital World." Council on Library and Information Resources. <https://www.clir.org/pubs/reports/conway2/index. html\#gen8>.

Darbellay, Frédéric. 2012. "Les Digital Humanities: vers une interdisciplinarité 2.0?" Natures Sciences Sociétés 20: 269-270. <https://www.nss-journal.org/articles/nss/abs/2012/o3/ nss120033/nss120033.html>.

Evans, Leighton, and Sian Rees. 2012. "An Interpretation of Digital Humanities." In Understanding of Digital Humanities, edited by David M. Berry, 21-41. Basingstoke: Palgrave Macmillan.

Flanders, Julia, Wendell Piez, and Melissa Terras. 2007. "Welcome to Digital Humanities Quarterly." $D H Q 1$ (1). <http://digitalhumanities.org/dhq/vol/1/1/000007/000007. html>.

Gardiner, Eileen, and Ronald G. Musto. 2015. The Digital Humanities: A Primer for Students and Scholars. New York: Cambridge University Press.

Hockey, Susan. 2004. "The History of Humanities Computing." In A Companion to Digital Humanities, edited by Susan Schreibman, Ray Siemens, and John Unsworth, 3-19. Malden, MA: Wiley-Blackwell.

Kirschenbaum, Matthew. 2010. "What Is Digital Humanities and What's It Doing in English Departments?" ADE Bulletin 150: 55-61. <https://www.ade.mla.org/bulletin/ article/ade.150.55>.

Kirschenbaum, Matthew. 2012. "Digital Humanities As/Is a Tactical Term." In Debates in the Digital Humanities, edited by Matthew K. Gold, 415-428. Minneapolis: University of Minnesota Press. <http://dhdebates.gc.cuny.edu/debates/ text/48>.

Kuhn, Thomas S. 1996. The Structure of Scientific Revolutions. Chicago: University of Chicago Press.

Liu, Alan. 2014. "What are the Humanities?" 4Humanities (blog), December 21, 2014. <http://4humanities.org/2014/12/what-are-the-humanities/>.

Pannapacker, William. 2013. "Stop Calling It 'Digital Humanities." The Chronicle of Higher Education, February 18, 2013. <http://www.chronicle.com/article/Stop-CallingIt-Digital/137325>.

Presner, Todd. 2010. "Digital Humanities 2.0: A Report on Knowledge." OpenStax CNX, June 8, 2010. <https://cnx.org/contents/JoK7N3xH@6/Digital-Humanities-20-AReport>.

Rockwell, Geoffrey, Peter Organisciak, Megan Meredith-Lobay, Kamal Ranaweera, Stan Ruecker, and Julianne Nyhan. 2012. "The Design of an International Social Media Event: A Day in the Life of the Digital Humanities." DHQ 6 (2). <http://www.digital humanities.org/dhq/vol/6/2/000123/ooo123.html>.

Ropars, Fabian. 2015. "Faut-il dire numérique ou digital?" blog du modérateur, February 11, 2015. <http://www.blogdumoderateur.com/numerique-ou-digital/>. 
Salah, Almila Akdağ. 2015. “Büyük Veri Çağinda Dijitalleşeri Bilimler.” Lecture announcement, Istanbul Sehir University. < http://sam.sehir.edu.tr/tr/series-of-talks-on-citiesbuyuk-veri-caginda-dijitallesen-beseri-bilimler/\#sthash.HDpesaDi.dpuf>.

Salvatori, Enrica. 2015. "L'identità dell'informatico umanista e la visione sistemica." Hypotheses Academic Blogs, January 23, 2015. < https://esalvatori.hypotheses.org/204>.

Schreibman, Susan, Ray Siemens, and John Unsworth, eds. 2004. A Companion to Digital Humanities. Malden, MA: Wiley-Blackwell.

Smith, Abby. 2004. "Preservation." In A Companion to Digital Humanities, edited by Susan Schreibman, Ray Siemens, and John Unsworth, 576-590. Malden, MA: WileyBlackwell.

Svensson, Patrik. 2009. "Humanities Computing as Digital Humanities." DHQ 3 (3). <http://digitalhumanities.org/dhq/vol/3/3/000065/000065.html>.

Tüfekçi, Şevket. 2015. "Yazınsal Çalışmalarda Dijital Yönelimler." Monograf 4: 91-130. <http://monografournal.com/sayilar/4/yazinsal-calismalarda-dijital-yonelimlermonograf-sayi-4.pdf $>$.

Viiri, Sampo. 2014. "Digital Humanities and Future Archives." The Finnish Institute in London (blog), June 6, 2014. <https://talkarttalksociety.wordpress.com/category/ archives/>.

Wiener, Norbert. 1948. Cybernetics: Or, Control and Communication in the Animal and the Machine. New York: J. Wiley. 
PART 1

\section{Archaeology}

